\title{
Computer generated self-care advice via web-based triage of complaints in primary care
}

\author{
Nicol Nijland, MSc \\ University of Twente \\ The Netherlands, \\ n.nijland@utwente.nl
Stef F.F. Verlinden, MD
Vivici Bv
The Netherlands
stef@ vivici.nl \\ Henk Boer, PhD \\ University of Twente \\ The Netherlands \\ h.boer@utwente.nl
}

\author{
Karlijn Cranen, MSc \\ Roessingh Research \& Development \\ The Netherlands \\ k.cranen@rrd.nl \\ Saskia M. Kelders, MSc \\ University of Twente \\ The Netherlands \\ s.m.kelders@utwente.nl
Julia E.W.C van Gemert-Pijnen, PhD
University of Twente
The Netherlands
j.e.w.c.vangemert-pijnen@utwente.nl

\begin{abstract}
Computer generated self-care advice systems are used in health care to support self-management and to respond to an increasing demand for care. Web-based triage is an innovative system aimed at empowering patients and saving costs while maintaining the same or better quality of care. Such systems consist of a symptom driven questionnaire for minor ailments based on the criteria: high frequency, no physical contact required to assess medical situation, and the possibility to rule out emergencies. We evaluated the feasibility of such a system for self-care. A retrospective analysis was carried out among 6538 patients by investigating the frequencies of complaints that have been entered to the system and the frequencies of the kinds of generated advice; online surveys $(n=192)$ based on behavioral theories were held to determine factors influencing compliance with generated self-care advice. Web-based triage can promote selfmanagement for minor ailments, especially for patients who have a positive attitude towards computer-generated advice. This positive attitude leads to intentions to follow up the advice and to actual follow up. To reduce unnecessary doctors' visits and to lower health care costs the system has to be brought more in to line with users' needs because the systems are more medical driven than user-centered.
\end{abstract}

Keywords; triage, Internet, self-care, primary care

\section{INTRODUCTION}

The rapid increase in chronic diseases and the ageing society places a burden on the health care system. The primary care system is one of the first systems to feel the effects of this burden. There is a potentially dramatic increase in doctor's visits to be expected in the years to come, which poses a huge human resources capacity problem [1]. On the other hand, patients become less dependent on face to face contact with their GP for medical care [2]. There are other ways for patients to get information about their problem and to help them decide whether or not a doctor needs to be consulted. Web-based decision systems support patients to make choices for treatment or screening on the basis of their preferences [3]. However, there is a lack of insight in the potential of these self-management systems to reduce unnecessary doctors' visits. Relatively often, patients visit their general practitioner (GP) for minor ailments. In the Netherlands, minor ailments, or self-limiting diseases like a sore throat, account for 40 to 80 percent of all consultations and influence the workload of GPs considerably $[4,5,6]$. In Great Britain, an estimated 100 to 150 million consultations are for potentially self-treatable ailments or ailments that can be managed by providing self-care advice [7]. Moreover, it appeared that GPs have the opinion that minor ailments do not require much attention [8], while patients expect more attention, making these visits unsatisfactory for both GPs and patients [9]. Computer generated self-care advice may fulfill the needs of both patients and GPs, as far as these systems are secure and provide evidence based information. While minor ailments, like a sore throat, in practice usually lead to a self-care advice, these kinds of complaints could be managed by Internet-based triage of complaints. Normally, triage is the classification of patient acuity that characterizes the degree to which the patient's condition is life or limb threatening, and whether immediate treatment is needed [10].

Nowadays, triage is also used for individual patients that seek guidance in determining the need and urgency for seeking care. Telephone triage and nurse advice call centers 
have been implemented in several countries to provide education, advice and instructions for self-care. However, telephone triage is dependent upon the caregivers' ability to make consistent and accurate decisions based on patients' responses. It appeared that the advice given by caregivers by telephone triage is rather inconsistent and inadequate [11]. A computer based clinical decision support system that meets the demands for high quality of care may be a more reliable support for self-care. Web-based triage for self-care management could be an adequate alternative to assist patients to make informed decisions regarding minor ailments. To our knowledge, findings about the impact of web-based triage on the care delivery process are scarce. There are some results about the usage of web-based triage in a college health setting. These findings indicate high use and good accuracy of web-based triage, providing education and advice about students' health care concern [12]. Also there are indications that web-based triage can save utilization costs (e.g., Emergency Room-visits) by getting people to the most appropriate place for care [13].

To date, little is known about the use of web-based triage systems and the impact of computer generated advice on compliance with the given advice. The objective of this paper is to find out for what kind of complaints web-based triage was used in primary care and to what extent the system supported self-care management. This study's research questions are: What kinds of complaints were submitted? What kind of advice was generated by the digital triage system? (Retrospective analysis) Which factors influence the intention to comply with computer generated advice? Which factors influence actual compliance and non-compliance? (Via online surveys among current users)

\section{METHODS}

\section{A. Description of the web-based triage system}

The web-based triage system www.dokterdokter.nl evaluated in this study provides fully automated diagnosis and advice, and no GP or caregiver is involved in the consultation process. This symptom-driven triage system (ISO 9000:2000 standards; certified TNO-QMIC) was developed with 25 'entry' complaints based on the criteria: high frequency, no physical contact required to assess the medical situation, and the possibility to rule out emergencies. Information required to asses the specific health situation is gathered through a dynamic questionnaire, varying on gender, age, and answers on previous questions about complaints. Each complaint leads to a specific triage module. Upon completion, consumers receive an online form with the computer generated diagnosis and advice, varying from "contact a doctor immediately' in urgent situations to a tailored self-care advice in case of minor ailments. The classification to contact a GP was based on telephone triage system (urgency, soon, short term, 24hours).

The system has two disclaimers. The first deals with legal conditions for using the system, for instance patients younger than fifteen were not allowed to use it. The second refers to medico-legal conditions; patients have to agree with the medical and legal policy of electronic care. The system is designed for patients to support them in a convenient way by means of computer-based interviewing; trough a question-and-answer system. The triage system was originally based on professional standards for telephone triage used in primary care for doctor assistants to determine whether a visit to a GP is necessary. Expected benefits of online patient-interviewing are the more accurate answers of patients than in face-to-face situations, and the possibility to give tailored education for self-care [14].

The web-based consultation process starts with identifying a health care complaint. Patients can indicate their complaint on a virtual body; for instance by clicking on the mouth or neck in case of a cough problem (see Screenshot 1).

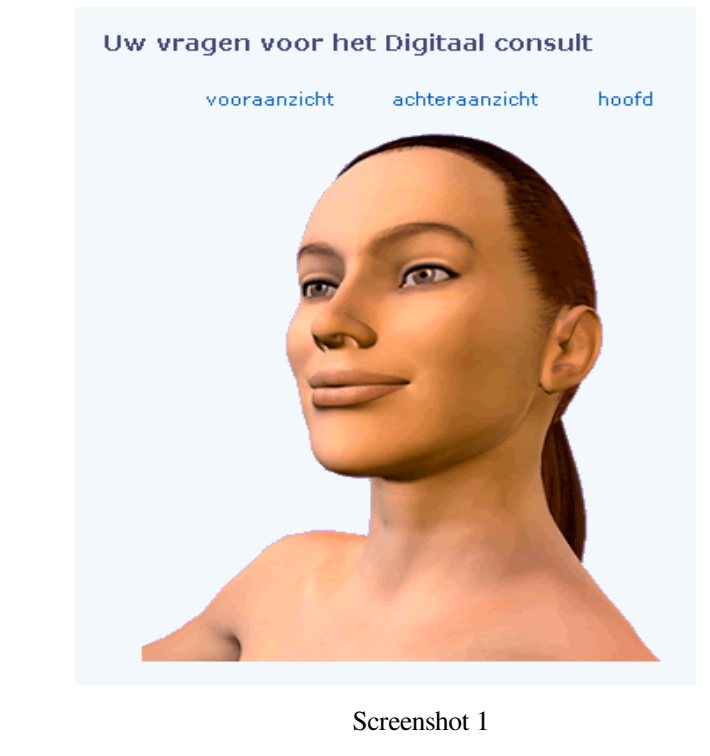

Subsequently, consumers have to run through the questions and answers related to the identified problem. For example, questions about coughing. The system asks for instance: "How often do you cough?" The kind of questions depends on the answers that were given. In the event of urgent symptoms, the triage application generates advice to visit a doctor. In the event of non-urgent issues, it generates tailored self-care advice. After completing the questions, the system provides advice varying from "contacting a GP as soon as possible" to getting tailored self-care instructions. Besides, information is given about the 
severity of the disease and the source of the medical information for reliability reasons. After completing the questionnaire a fully automated tailored self-care advice was given, see the text box for a cough problem (Text box 1). The advice entails a diagnosis and detailed self-care instructions.

\section{Example of self-care advice:}

- Although your complaints can be (very) irritating, there are no reasons to worry

- You have a common disease, you do not need to visit your GP

- Your complaints indicate an upper airway disease, caused by a virus or a bacteria

- This is a non-severe disease, which recovers spontaneously within 1 to 2 weeks

- What a doctor can do, what you can do

\section{B. Research instruments}

Text box 1

In the retrospective study, we analyzed the triage consults of 13133 unique visitors that during a period of 15 months had visited www.dokterdokter.nl. Of 6538 users, who started a consult and went completely trough the triage system, we examined the frequencies of various complaints and the types of advice provided by the system. In this study, we used an existing database, where 'clicks' per user were stored while passing through the web-based consult. To determine which factors were related to compliance with the provided advice, a prospective online survey $(n=192)$ was carried out. Following the advice, respondents filled out a questionnaire, which was based on the Theory of Planned Behavior and the Protection Motivation Theory. Likert scales (ranging from -2 to +2 ) and summated rating scales were used to measure usability of the system, satisfaction with the generated advice, attitude, subjective norm, self-efficacy, perceived severity of the complaint, response cost and response effectiveness. Yes/No answers were used to assess intention to follow up the advice. Respondents that agreed to participate in further research $(n=36)$ received a follow-up questionnaire after three months, which assessed actual compliance with the advice. Both surveys are available upon request of the correspondence author (n.nijland@utwente.nl).

We focused on variables as "attitude towards advice", "self-efficacy, that is the ability to act upon advice", "social influence of important others, like family on compliance", and "perceived severity of a complaint"; all based on health behavior theories. The reliability of these variables appeared sufficient: attitude towards advice $(\alpha=0.91)$; subjective norm $(\alpha=0.79)$; self-efficacy $(\alpha=0.89)$; perceived severity of a complaint $(\alpha=0.84)$. We carried out a regression analysis to assess the factor that has the strongest impact on compliance. It appeared that not all patients responded to all questions of the online survey. Therefore, the descriptive results vary in numbers of respondents. The regression analysis is carried out with completed surveys.

\section{RESULTS}

\section{A. Actual usage of the system}

On average, the system was used for 29 consults per day. Figure 1 presents the number of persons that started the consultation, submitted a complaint and received an advice. Out of 13133 patients who started a consult, 6538 entered a complaint and 3812 completed the consultation process and received a care advice; 29 percent of all started consults. There are two critical points in the consultation process regarding the high rate of drop-outs. One concerns the identification of the complaint. Of the patients that entered the system, 50 percent left it when they had to identify their complaints on the virtual body. The second critical point is the number of patients that left the system just before getting advice. We don't know the reason for this behavior. Presumably, the system has a therapeutically effect and patients stop when their "hunger" for information is satisfied. Besides, users might have faced some technical problems with using the system.

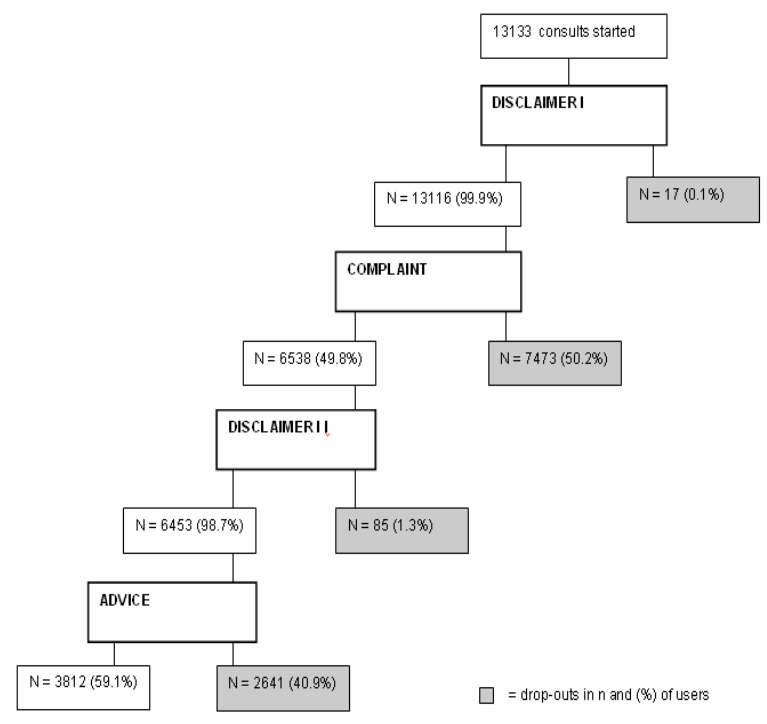

Figure 1. Consultation process

Figure 2 gives an overview of the type of complaints for which the system was consulted. The most frequently submitted complaints were common cold symptoms, such as cough and a sore throat $(21.9 \%)$, itch problems $(13.2 \%)$, urinary complaints $(11.7 \%)$, diarrhea $(10.2 \%)$, headache $(8 \%)$, and lower back pain $(7.5 \%)$. Together, these complaints covered more than 70 percent of all submitted complaints. The frequency of complaints is comparable with the complaints for which GPs are most frequently 
contacted in the Netherlands [15]. In general, for these complaints self-care advices could be given more often.

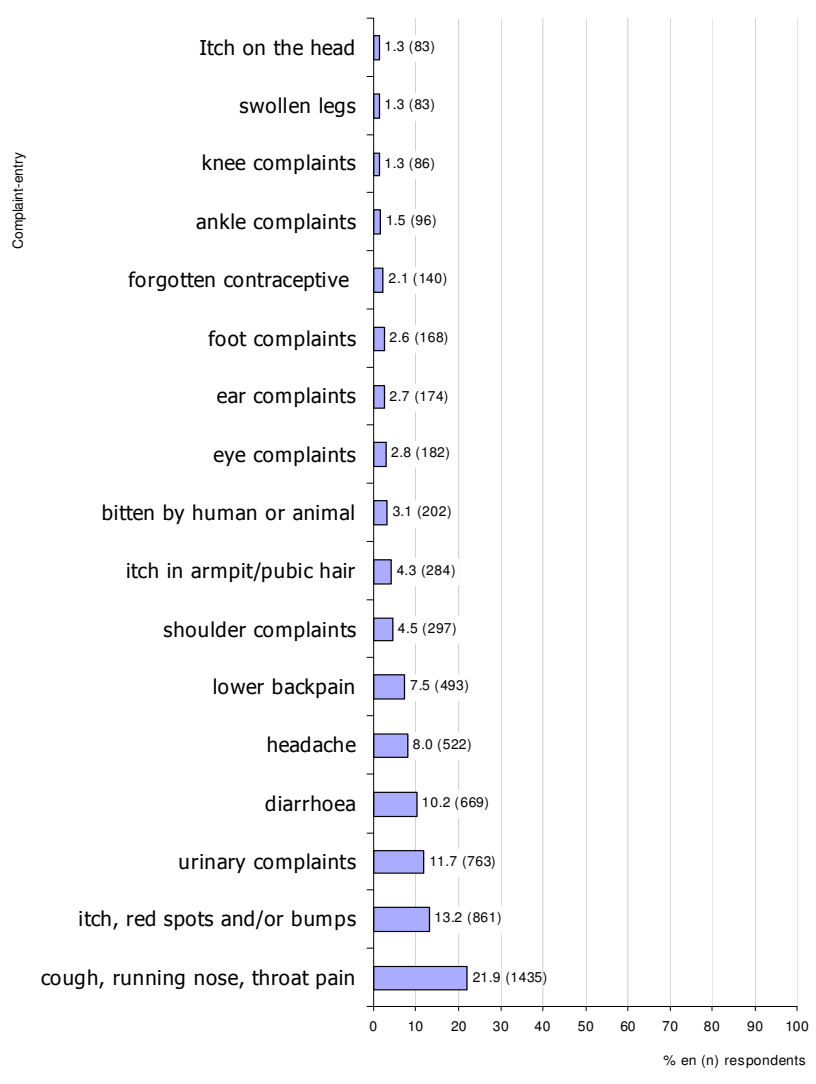

Figure 2. Overview of complaints $(\mathrm{n}=6538)$

Figure 3 presents an overview of the generated advice. The classification of the "contact a doctor advice" was based on the national health care standards for triage by telephone. The greater part of advice referred to a doctor's contact (85\%), and in 15 percent of the cases a fully automated problem-tailored self-care advice was provided. The finding that only in $15 \%$ of the cases a self-care advice was given, may not contribute largely to the reduction of GP visits. The patients described the complaint they entered the consult with. Common cold complaints were entered most. A few, 9 percent, of the respondents mentioned so called 'taboo complaints' as urinary complaints and complaints that had to do with menstruation. In table 1, the relation is shown between frequency of complaints and generated advice. For relatively infrequent complaints, like forgotten oral contraceptive, mostly a tailored self-care advice was given. For high frequency complaints, in general, the advice was given to contact a doctor. These findings indicate that the system is too defensive and may not contribute to saving costs.

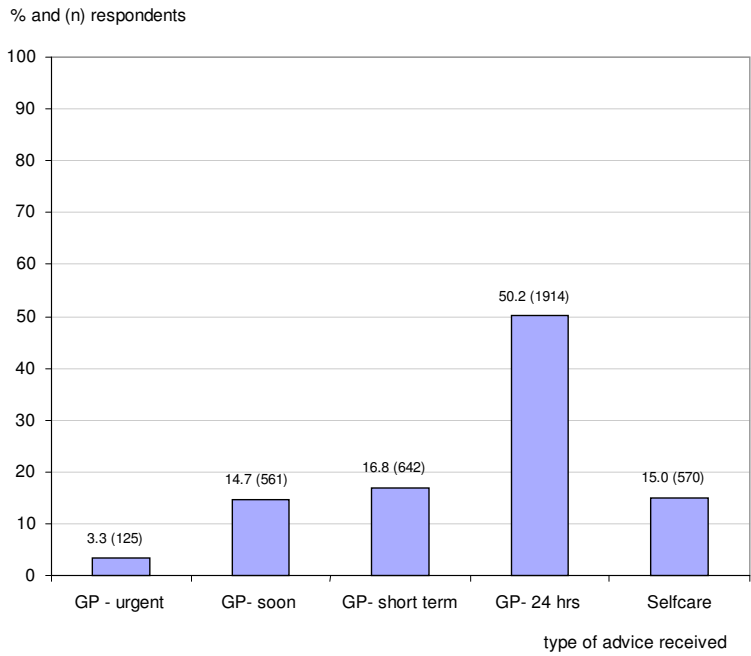

Figure 3. Overview of generated advice $(\mathrm{n}=3812)$

$B$. Results of the online surveys: compliance with generated self-care advice

The questionnaire showed that the greater part of the current users were woman $(n=127,68 \%)$ and middle $(\mathrm{n}=101,54 \%)$ to highly educated $(\mathrm{n}=55,29 \%)$, varying from vocational schools to university, and aged between 16 and 35 years $(\mathrm{n}=107,57 \%)$. The majority of the current users $(n=103,58 \%)$ spent between zero and two hours on the Internet per day. Most knew the web-based triage system by surfing on the Internet $(n=73,41 \%)$ and by advertisements of the health insurer $(n=62,35 \%)$. At the time of filling out the questionnaire, most patients $(n=104$, $69 \%$ ) visited the web-based triage system for the first time. Patients $(n=83,44 \%)$ got allowance from their health insures to use the digital consult freely, however there is a part of the patients $(n=78,42 \%)$ who do not know who pays for this service. Patients used the triage system to gather information about their complaint $(n=72,49 \%)$, more than for deciding whether a doctor has to be contacted $(n=38$, 26\%). The system was mainly used for complaints like cough and sore throat $(n=72,75 \%)$, a minority $(n=6,9 \%)$ used the system for taboo complaints (sexual, urinary). Preceding the triage consult nearly half of patients $(n=73$, $49 \%$ ) had the intention to visit a GP for their complaint. Of all patients $(n=72)$, most expected a self-care advice $(n=30)$ and less expected a GP-advice $(\mathrm{n}=22)$, or had no expectations at all $(\mathrm{n}=20)$. Patients, who expected a GPadvice $(n=22)$, all received such an advice, while among the patients who expected a tailored self-care advice $(\mathrm{n}=30)$, the majority $(63 \%)$ received a GP-advice. In most cases a contact a doctor (GP-advice) was given $(n=54$, $76 \%$ ). 
Table 2 presents the evaluation of the web-based triage system. In general, it could be said, that users have no clear mental representation of what they can expect from a triage consult. All scores were neutral to slightly positive. This can be explained as a lack of experience. It appeared that only a minority had used the web-based triage system more than once.

A regression analysis revealed that a positive attitude $(\mathrm{p}<0.001)$ towards the advice was strongly related to the intention to comply. Actual compliance was strongly related to intention to comply with advice (Table 3 ).
Apparently, people stick to their plans. A positive attitude towards advice was strongly related to the perceived usefulness of the advice, as reflected in understandability, reliability of information, applicability in daily life, and effectiveness. It appeared that 57 percent actually had complied with the advice. Patients that complied with the advice were higher educated (55\%) and frequent users of medication (40\%); besides the received advices corresponds in most cases (84\%) with expected advice. Reasons for noncompliance were lack of confidence in the advice and fear to follow-up the provided advice.

TABLE 1. Overview of generated advice related to frequent and infrequent complaints (in \%)

\begin{tabular}{|c|c|c|c|c|c|}
\hline \multirow[t]{2}{*}{ Complaints/advice $(\mathrm{N}=3812)$} & \multicolumn{4}{|c|}{ Contact a doctor } & \multirow{2}{*}{$\begin{array}{l}\text { Tailored self-care } \\
\text { advice/diagnose }\end{array}$} \\
\hline & Urgent & Soon & Short-term & $24 \mathrm{Hrs}$ & \\
\hline Common cold complaints $(n=877)$ & 14.3 & 28.8 & 10.5 & 32.2 & 14.3 \\
\hline Itch, red spots and/or bumps $(n=462)$ & 0 & 20.3 & 0 & 52.4 & 27.3 \\
\hline Urinary complaints $(n=417)$ & 0 & 0 & 22.1 & 76 & 1.9 \\
\hline Diarrhea $(n=435)$ & 0 & 0 & 55.4 & 19.5 & 25.1 \\
\hline Headache $(n=305)$ & 0 & 25.7 & 6.3 & 63.2 & 4.9 \\
\hline Eye complaints $(n=138)$ & 0 & 2.2 & 11.6 & 60.9 & 25.4 \\
\hline Foot complaints $(n=102)$ & 0 & 0 & 0 & 77.5 & 22.5 \\
\hline Forgotten contraceptive $(n=80)$ & 0 & 0 & 0 & 51.3 & 48.8 \\
\hline
\end{tabular}

TABLE 2. Evaluation of web-base triage

\begin{tabular}{lll}
\hline Evaluation web-based triage consult & Mean score & Scale \\
\hline Attitude towards advice & 0.42 (neutral to positive) & $($ scale -2 to +2$)$ \\
Self-efficacy & 1.0 (positive) & $($ scale -2 to +2$)$ \\
Influence of family etc. on intention to comply & 1.3 (neutral) & $(\text { scale }-10 \text { to }+10)^{*}$ \\
Perceived complaints & -0.24 (slightly severe) & (scale -2 to $+2(-2=$ non severe) \\
Intention to comply with advice & 0.49 (neutral to positive) & (scale -2 to +2$)$ \\
\hline 5-point scale ranging from -2 (negative) to +2 (positive), *social norm: a construct of two variables: "do you think your family finds it important" (-2 to +2); "to what extent the opinion of your family is \\
important for you" (1 to 5)
\end{tabular}

TABLE 3. Predictors of intention to comply with advice

\begin{tabular}{llll}
\hline $\begin{array}{l}\text { Determinants of intention to comply with advice } \\
\left(\mathrm{R}^{2}=.53\right)\end{array}$ & Beta & Determinants of actual compliance with advice $\left(\mathrm{R}^{2}=.47\right)$ & Beta \\
\hline Attitude & & $.69 * * *$ & Attitude \\
Subjective norm & .05 & Subjective norm & .21 \\
Self-efficacy & .08 & Self-efficacy & .26 \\
Severity of complaint & .07 & Severity of complaint & .15 \\
& & & Intention to comply \\
** $\mathrm{p}<.01 ; * * * \mathrm{P}<.001$ & & & \\
\end{tabular}

\section{CONCLUSION AND DISCUSSION}

\section{A. Retrospective study and online survey}

Based on the findings of the retrospective study, we can conclude that the current web-based system for triage of complaints has a potential to reduce costs and to promote self-care, although the system is not advanced enough to support the decision making process for self-management, yet. There was a high rate of drop-outs, especially before entering a complaint (50\%) and just before receiving a care advice (40\%). Given the high rate of drop-outs, the question arises what the motivations of the users were. We lack insight in the motivations of the drop-outs of the webbased triage system. Based on the retrospective study we only have insight in the moments users quitted the system, not in their motives for this behavior. In-depth interviews are needed to get insight in the motives and barriers of drop-outs. On the other side, the results of the retrospective 
study were comparable with the survey results of current users with respect to the type of submitted complaints and the type of generated advice.

The purpose of the system is to support users in their decision when to contact a GP. But, it seemed the patients used the system to check assumptions about their illness rather than to make firm decisions about visiting a doctor. The greater part of provided advice referred to a doctor's visit $(85 \%)$. This indicates that the system was more medical-driven than user-centered, considered the defensive rigidness of the system. Another finding was that high frequency complaints (like cough) led to the advice to visit a doctor, while patients with low frequency complaints (like itch) received a tailored self-care advice. Our findings are consistent with the findings of other studies about a corresponding web-based triage system. It appeared that a web-based triage system, operable in the United States, was mainly used by women for non-urgent complaints, comparable with complaints a GP is consulted for most [12].

On the side of the value of web-based triage the question arises whether the defensive medical legal system (GPreferrals) is an unnecessary barrier for advanced tailored self-care. This requires a rethinking about the practicality of the triage urgency system that is based on telephone nursing triage instead of patients' self-care needs. Clear policy about and innovative legislation about practicing online consultation is needed to maximize the accessibility and effectiveness of web-based triage and to clear up responsibility for online consulting.

The prospective survey study revealed that attitude towards the advice was strongly related to intention to comply with the advice, while intention to comply determined actual compliance with the advice. This means that web-based triage can promote self-management of minor ailments for patients who have a positive attitude towards computer-generated advice. This positive attitude leads to intentions to follow up the advice and to actual follow up. Therefore, web-based triage can contribute to a more efficient primary care system; it facilitates the gatekeepers' function. This implies that empowering patients by means of web-based triage requires interventions to instruct and motivate users; which is usually not scheduled by implementing health care technologies.

A limitation of this study is the limited response on the online surveys and the incompleteness of the responses; patients did not respond to all questions. Reasons could be the limited use of web-based consultation in general. It appeared from another study, that only 9 percent of the GPs in the Netherlands provided this service for their patients [16], and it is not allowed to use it without a pre-existing relationship with a GP. Other explanations could be the period of examination, summer time, and the method used.
Disadvantages of online surveys are the inaccurateness of the response, people have the tendency to skip answers and to zap or scroll like visiting a website [17]. On the other hand, the results are comparable with findings of other studies about web-based triage $[12,13]$.

\section{B. Opportunities web-based triage}

Although there are several start-up problems, we foresee opportunities for web-based triage. Online patient interviewing via web-based triage can be used for diagnoses and early detection of risks, for instance for preoperative screening and handling taboo complaints. We know from our research on urinary complaints that web-based triage can promote effective treatment of taboo complaints, like urine-incontinency [18]. Also it could be used in preparation for a GP visit [16]. From prior research we know that self-management and reduction of uncertainty were the main drivers for using web-based triage [19]. To support self-care and decision making, it is important to match expectations of users and technology. Patients were confronted with a high percentage of referral to a doctor; higher than they expected. So, there is an imbalance between the central idea of web-based triage and the intended use of it. Since self management is the focus of electronic care, we need to evaluate more in depth patients' need for autonomy and their readiness to make decisions about their health care.

To empower patients an e-service package might be better solution for self-care support than a stand-alone fully automated facility. For instance, web-based triage combined with online education and lifestyle interventions may have good prospects; it appeared for instance that patients with chronic complaints preferred online consultation with instructions for self-care [20].

For reasons for cost savings web-based triage can reduce overuse of emergency departments and foster appropriate use of doctor's office visits [13]. Triage centers, which determine the specialized facility patients should go to, can be a solution for saving money by improving scheduling and providing care at the most appropriate place. Reduction of utilizations costs is needed, because the overuse of emergency department visits. Most of these visits fail to meet criteria for emergent (i.e., requiring care within 15 minutes) or urgent (within one hour) care [21,22]. Especially for the chronically ill who are overrepresented among emergency department visitors, web-based triage systems as part of a chronic disease management program could reduce uncertainty by delivering alternative access to care and more adequate communication for selfmanagement $[22,23]$. 


\section{REFERENCES}

[1] M. Orchard, E. Green, T. Sullivan, A. Greenberg, and V. Mai, "Chronic disease prevention and management: implications for health human resources in 2020," Healthc Q 2008;11(1):38-43.

[2] S. Katz and C. Moyer, "The emerging role of communication between patients and their providers," J Gen Intern Med 2004;19(9):978-983.

[3] G. Eysenbach, "Consumer health informatics," BMJ 2000;320(7251):1713-1716

[4] S. Kooiker, "Illness in everyday life. A health diary study of common symptoms and their consequences," Utrecht: Nivel (Netherlands Institute for Health Services Research), 1996.

[5] B.V. Rambihar, "Minor illness is no minor matter, e-letter, BMJ 19 May 2001.

[6] A. van den Brink-Muinen, A.M. van Dulmen, H.P. Jung, and J.M. Bensing, "Do our talks with patients meet their expectations?" J Fam Pract 2007;56(7):559-568.

[7] Z. Whittington, K. Hassell, J. Cantrill, and P. Noyce, "Care at the chemist: a question of access. A feasibility study comparing community pharmacist and general practice management of minor ailments," Manchester: School of Pharmacy and Pharmaceutical Sciences, 2001.

[8] B.V. Anonymus, "39 percent of GPs time lost on minor ailments,” Pharm J 1997;258:499.

[9] A. Plass, D. Timmermans, and G. van der Wal, "Decreasing the number of consultations for minor illness of Turkish and Dutch inhabitants of a deprived area in the Netherlands: an intervention study," Fam Pract 2005;22:51-57.

[10] N. Gilboy, P. Tanabe, D.A. Travers, D.R. Eitel, and R.C. Wuerz, "The emergency severity index implementation handbook: a five-level triage system," Des Plains, IL: Emergency Nurses Association, 2003.

[11] H. Derkx, "For your eras only. Quality of telephone triage at out-of-hours centres in the Netherlands," Dissertation University of Maastricht, 2008.

[12] M.L. Sole, P.L. Stuart, and M. Deichen, "Web-based triage in a college health setting: university researchers prove accuracy of DSHI web-based triage," J American College Health 2006;54(5):289-94.

[13] "DSHI Systems debuts FreeMD the web's first virtual doctor,” DSHI Systems Press Release, April 2008.

http://www.worldcongress.com/events/HR08000/pdf/news/DSHI_ PR_4_21_08.pdf.

[14] J.W. Bachman, "The patient-computer interview: a neglected tool that can aid the clinician," Mayo Clin Proc 2003;78:67-78.

[15] "Top 20 van het aantal (deel)contacten onderverdeeld naar diagnose (ICPC)" (Reasons for encounter: top 20 of ICPC-codes, 2005), Utrecht: Nivel (Netherlands Institute for Health Services Research), 2006.

http://www.nivel.nl/oc2/page.asp?PageID=10527\&path=/Startpun t/subsites/LINH 2006/Cijfers/Aandoeningen/A3. Top 20 aantal contacten per aandoening.

[16] N. Nijland, J. van Gemert-Pijnen, H. Boer, F. Steehouder, and E.R. Seydel, "Evaluation of Internet-based technology for supporting self-care: problems encountered by patients and caregivers when using self-care applications," J Med Internet Res 2008;10(2):e13.

[17] K.B. Wright, "Researching Internet-based populations:

advantages and disadvantages of online survey research, online questionnaire authoring software packages and web survey services," Journal of Computer-Mediated Communication 2005;10(3):1083-6101.

[18] M. de Bruin, W. de Waard, H. Leliefeld, J. Zambon, P. Kil, B. Wijsman, F. Bentvelsen, and M. van Balken, "Multicentervalidatie van het internet-diagnose computer programma MediArts voor urine incontinentie bij vrouwen," (Multicenter validation Internet-diagnosis for urine inconsistence among women), Ned Tijdschr Urol 2006;6:176.

[19] N. Nijland, J. van Gemert-Pijnen, F. Verhoeven, H. Boer, E.R. Seydel, The contribution of different approaches of webbased consultation to the quality of care: experiences of caregivers and care consumers, Technology and Health Care 2007;15(5):348349.

[20] F. Verhoeven, L. van Gemert-Pijnen, K. Dijkstra, E. Seydel, N. Nijland, and M. Steehouder, "The contribution of teleconsultation and videoconferencing to diabetes care: a systematic literature review.” J Med Internet Res 2007;9(5):e37. [21] M. Wilson and K. Nguyen, "Bursting at the seams, improving patient flow to help America's emergency departments, urgent matters," The George Washington University Medical Center, School of Public Health and health services, September 2004. www.harrisinteractive.com

[22] H. Foekema, C. Hendrix, "Spoed moet goed, een onderzoek naar de spoedeisende zorg," (Research about the functioning of emergency departments in the Netherlands), January 2005. www.npcf.nl/uploads/files///spoedmoetgoed.pdf.

[23] Emergency department utilization in California, "Survey of Consumer Data and Physician Data conducted for California HealthCare Foundation," October 2006.

www.harrisinteractive.com. 